TITLE: AN ANALYSIS OF THE DEUTERON DISTRIBUTION EMERGING FROM THE FMIT RFQ

\title{
MASTER
}

AUTHOR(S): Grenfell P. Boicourt, Bruce 2. Chidley, Kenneth R. Cranda 11, Robert A. Jameson, Richard H. Stokes, and Thomas P. Wangler

SUBMITTED TO: Particle Accelerator Conference
March 11-13, Washington, DC

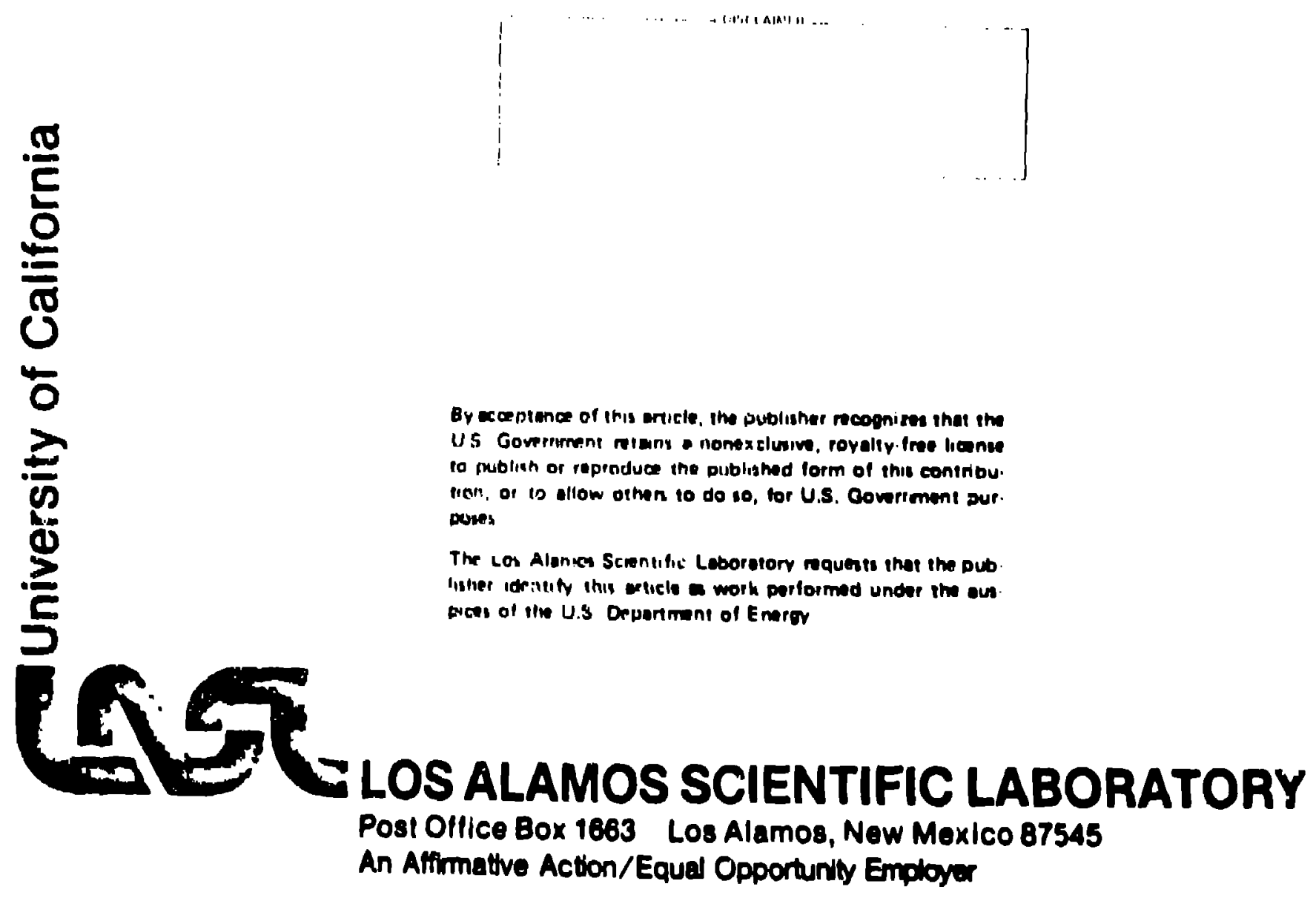

Form No. 020 R3 


\section{ANALYSIS OF THE DEUTERON DISTRIBUTION EMERGING FROM THE FMIT RFQ*}

G. Boicourt, d. Chidley, ${ }^{* *} K$. Crandall, R. Jameson, R. Stokes, and T. Wangler Los A lamos National Laboratory, Los Alamos, New Mexico 87545

\section{Sunmary}

Knowledge of the propertles of the input beam is necessary for evaluating losses in a drift-tute linac (UTL). The FMIT (Fusion Materials Irradiation Test Facility) accelerator w1ll use a Rasto-Frequency Ouadrupole (RFQ) structure as the first accelerator stage that feeds a or ift-tube section. As the first step in evaluating beam spill in the drift-tube section and output transport, we studied the properties of the beam exit ing the RFQ. An RFQ, berause of its electric-field focusing, allows particles of any energy to pass through its structure. Thus, its output is essentially different from the output of an accelerator that uses strong focusing magnets. The study presents surfaces giving the number of particles as a function of position in various planes of phase space. Two PARMILA codes were used: a standard longitusinal positton-dependent code, and a timedipendent code. The codes give siightly different answers.

\section{Introduction}

The FM!T acceler.tor has stringent ifrits on the allowed beam spill in the drift-fute sertion and the High-Energy Beam Transport (HEBl). Thr beam sfill In the critical sections mainly will be determined by the properties of the bedm emerging from : the RI $U^{*}$ that feeds the or ift-tube linac.

Of primary irterest is the toent if ication of those beam regions that give rise to particles that will be lost in the drift-tube section. He expect that such part - les will be chardrterized by having either a single extreme in one of the six phase-space dimensions or a relative extreme in one of the twodimensional phase planes. inus, low energy by tiself is enough to cause a particle to be lost, but the wiung comi inat ion of phase and energy also will resule in loss. This snould explain our internest in six-dimensiunal beam properties.

\section{Methou}

The destan of the FMIT AFO is described in another paper presented at this mect ing.?

Computer simulations of beains froin the FMIT RFO were made, using two partic le-dynamics codes:

PARMTEQ $B$ and PARMTEO $C$. PARMTEQ $B$ is a rode in whitch the independent vartable is the oxtol positiin (z) in the arcelerator and will be referred to as thr 2 -conde. PARMTEQ $C$ uses time as the variable of integralinn and will be referred to as the T-code. The use of two codes gives us two silghtly different mude's of reslity, because slightly different formulations are forced by the use of different independent yorlatiles.

The electrical focusing in 'Fu, allows particles of all energies to tral rse the accelerstor. The number uf law-energy particles lost from, or not captured in the bucket, may be small; therefore.

\footnotetext{
- Twork performed under the ausplces of the US l)eportment of Energy.

- Chalk River Nuclear Laboratory. Chalk River. Ontarto, Canada.
}

consideratle effort was made to use enough particles to get reasonable statistics. The results presented below are based on individual runs, with the initial number of particles set at more than 42000 .

The beams emerging from the RFQ were analyzed in several ways. Histograms were made of the distributions of the particles in each of the six dimensioris of phase space. Three-dimensional surfaces, showing the particle distributions in various two-dirensional phase planes, were made by sorting the particles into rectanjular bins in the desired plares. Stanoard rms methods were used to calculate emittances and the Courant-Snyder beam parameters

Table I gives the properties of the bein's trensverse input and output. The emittances are normulized and in units of cm-mrad, and are to be multiplied by $\pi$ to obtain an emittarice area. The a's are unitiess and the $B^{\prime} s$ have units of $\mathrm{cm} / \mathrm{rac}$. The output beam includes all particles leavino the pro, even those well out of the bucket in energy.

\section{Results \\ Tatin I}

Transverse Properties of RFQ Input and Gutpu: Beam

$$
\begin{array}{llllll}
a_{x} & B_{y} & E_{x} & a_{y} & B_{y} & \varepsilon_{y}
\end{array}
$$

Input to RFil

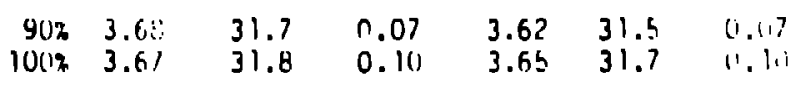

OulDs: trom RTL

\begin{tabular}{|c|c|c|c|c|c|c|}
\hline 90 & $\begin{array}{l}3 . \\
2 .\end{array}$ & $\begin{array}{r}120.0 \\
61.4\end{array}$ & $\begin{array}{r}0.18 \\
101 . '\end{array}$ & $\begin{array}{l}-4.99 \\
-2.17\end{array}$ & $\begin{array}{r}117.5 \\
51.3\end{array}$ & $\begin{array}{r}0 . \\
i t 6 .\end{array}$ \\
\hline & & $\begin{array}{r}11110.7 \\
24.7\end{array}$ & $\begin{array}{r}0.21 \\
93.86\end{array}$ & $\begin{array}{l}-4.66 \\
-0.78\end{array}$ & $\begin{array}{l}96.3 \\
20.0\end{array}$ & \\
\hline
\end{tabular}

The transveren rurfaces characterizing the bein prinering from the FMIl RFQ do not show noticeat le differences betwein tho $T$. and $:-$ condes. Surfacess of $x-x^{\prime}$ and $y-y^{\prime}$ are shewn in Flas. I and $a$ a heth appen in be roughly clliplical, with the partic le denelty

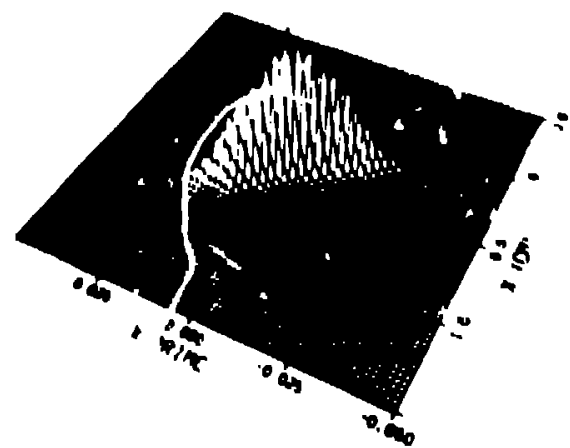

Fig. 1. The $x-x^{\prime}$ surface of the beam ot the exit of thr RFQ. (T-code) 


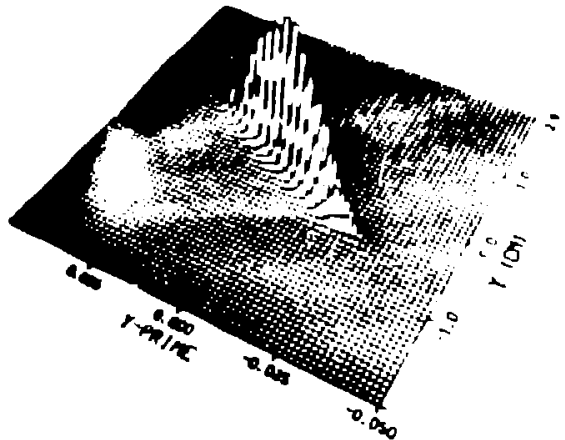

Fig. 2. The $y-y^{\prime}$ surface of the beam at the exit of the RFO. (T-code)

falling off along the major axis, in wat appears to be doughly Gaussian manner. Along the minor axis, the fall-off seems more sudden. Histograms of the beam in the four transverse coordinates tend to confirm these observations about the $x-x^{\prime}$ and $y-y^{\prime}$ surfaces.

The beam distribution in physical transverse space is shown in Fig. 3. The RFQ ends at the point in the cell where the beam is nearly round. The "mountaln" is quite symmetrical and the only unusual feature is the prasence of "lava steeple" in the center of the crater. The "steeple" appears in both $T$ - and Z-code computations and seems to be character istic, because ti also appears in the output of other RF Q's.

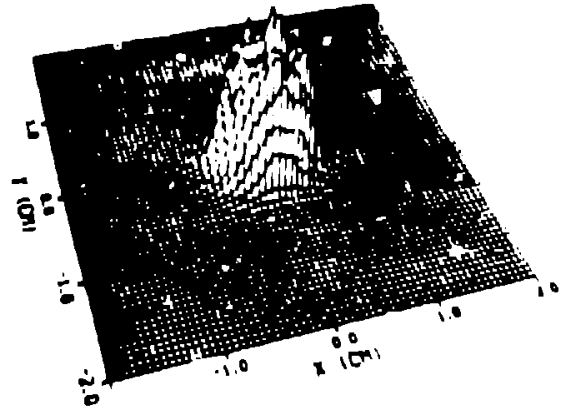

Fig. 3. The $x-y$ surface of the beain at the exit of the RFQ. (1-code $)$

Longltudinally, the agreement between the two codes is not as satisfactory. Two views of the $4 W$ surface produceo by the $T$-code are shown in $F$ los. 4 and 5 . The destan values for the outpist phase and energy are $-30^{\circ}$ and $2.0 \mathrm{MeV}$. F tgures 6 and 7 show ciic $-W$ surface produced by the 2 -code.

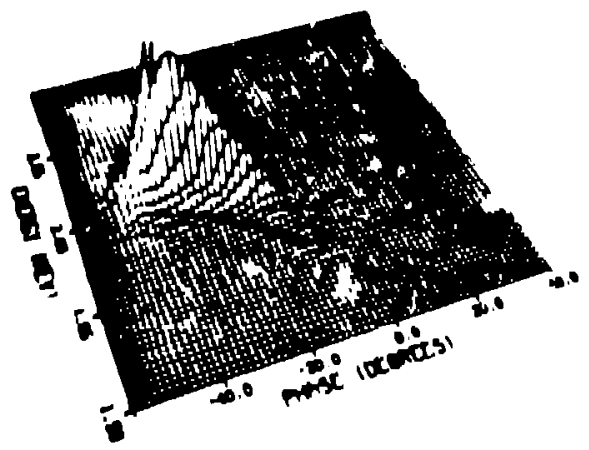

F19. 4. The $\rightarrow W$ surface of the RFO becm produced by the T-code.

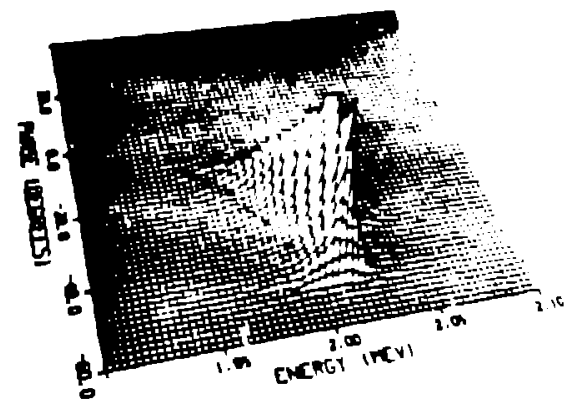

Fig. 5. Same surface as Fig. 4, but viewed from another angle.

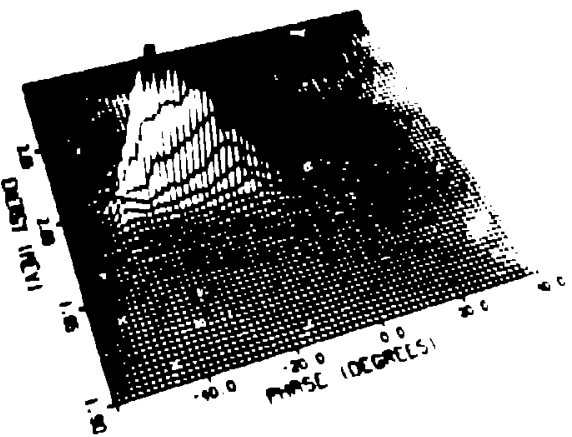

Fig. E. Wh surface of the RFQ beam produced by the $Z$-code. Compare with Fig. 4.

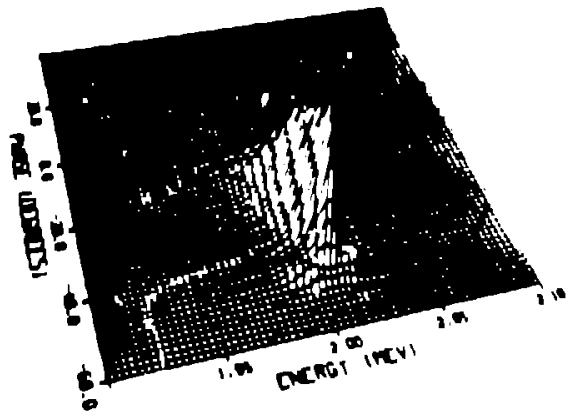

Fig. 7. Surface of $F$ 1g. 6 viewed from another angle. Compare with Fio. 5.

These surfaces do not show the ent tre extent of the beam. The fu?l beam contains $360^{\circ}$ phase spread, and an energy spread from $0.03 \mathrm{HeV}$ to $2.09 \mathrm{Me}$. The surfaces shown contain about $97.8 \%$ of the output bean for the $T$-code and about $99.2 \%$ for the 2 -code.

The $z$-code $-W$ surface seems to have an almost rectangular boundary. The $\rightarrow H$ surface produced by the $T$-code is more fishlike, having tall projecting toward the low-energy and posittve phase.

The low-energy portion in the T-code run is substantially areater than for the 2 -code run. Th1s is evident from comparison of the logarithmic histogrems show li, Flos. 8 and 9

In thase simulations. All particles exiting the RFQ were wlthin the transverse acceptance of the OTL. Particles with energles below 1.9 MeV are 


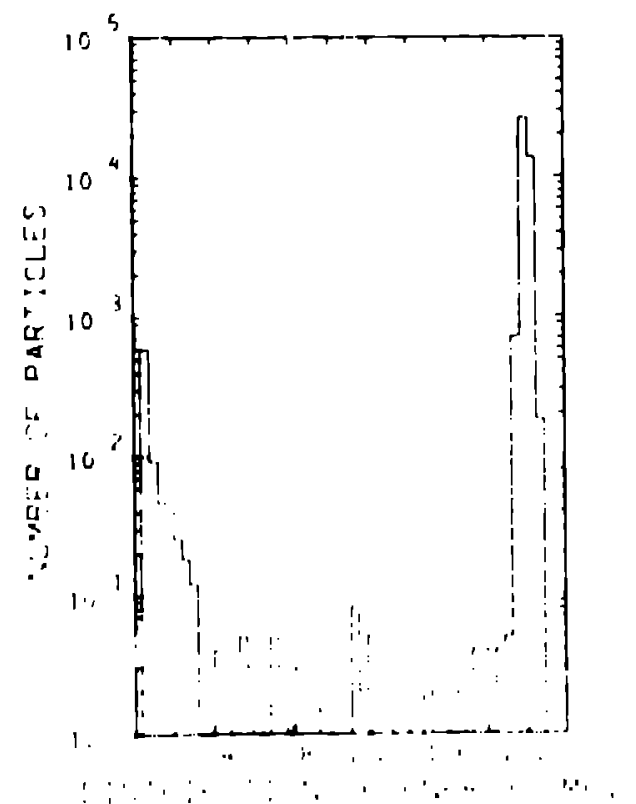

Fig. 8. Loqarithmic histogram of the eneray distribution exiting the pry. T-eciclo

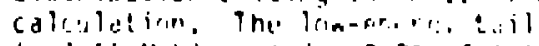

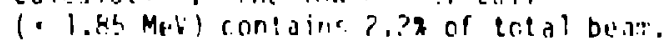

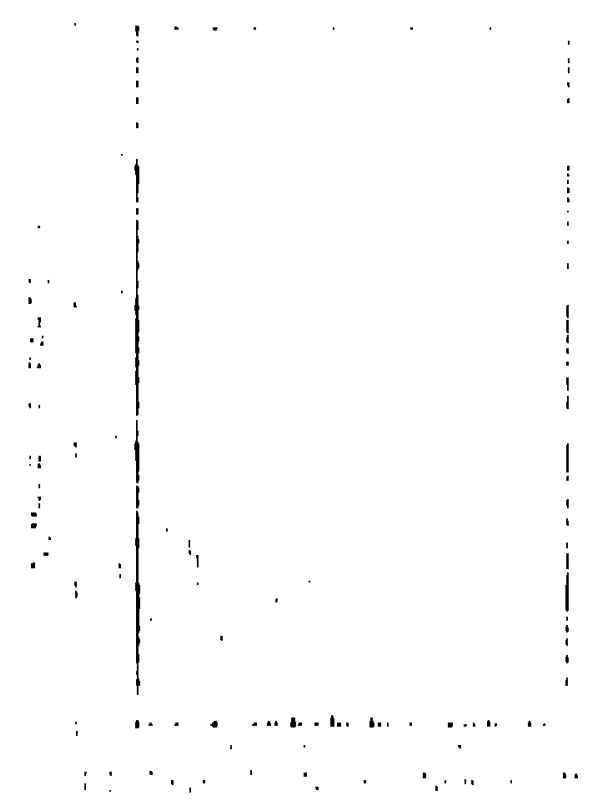

19.9. 9. Logariehmic histourane of the beam energy distribution exteilig the RTU. $i$-condo calculation. I ow-ennryy tall is I, B! MeV) amuints li (), Mt of the lcilal beill. almost entirely responstble for the numerically ouserved losses in the FMIT DTL section, when RFQ calculated inpst is used. Therefore, the oifferences shown in $F$ igs. 8 and 9 are of considerable importance in designing the DTL portion to accommodate the power deposited by the lost portion of the beam. The extreme low-energy portion of the beam (below $0.1 \mathrm{MeV}$ ) amounts to about $1.0 \%$ of the outpui beam for the $T$-code and to less than $0.1 \%$ for the 2 -code. Except for the effect on the low-energy performance losses, the code differences have negligible impact on the DTL. In simulations, ne particle lost in the DTL has hao energy greater than $4 \mathrm{MeV}$.

\section{Summary and Conclusions}

The output beam of the FMIT RFQ appears to exhibit the expected behavior in the transverse coordinates of phase-space. In the longitudinal coordinates $\$ W$, the twic dynamics codes give somewhat different results. At present, we cannot fully explain these differurces. Two known causes are:

1. The sface-charge impulses arn applled at different lungiludind positions.

$\therefore \quad T_{1}$. einjection of particies mive thar $: \pi$ in pildse from back into the bunch ars: handind differently.

We know that the co es of the bunches ari adite simlar. We are detively investioat ing the code differences and oplieve that gredter urderstanitiog will rosi't from conparisons of the two cudic.

\section{References}

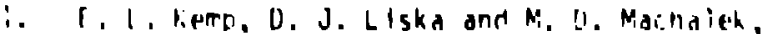
"ih. fuston Matertals Irradiation Test (FM: : Ac, lepator," Proc. 1979: Inear Accelerator [ill:f., Sen', 10-14, 1979, Monlaik, N,Y. (Bi*oohlianen Na'tons, Lahoralery, llpton, N) BN: $\quad 5 / 134$.

7. R. Slakes, T. Hangler, and k. Cindall, "ince Radic Trequency Qujurupole: A Nen Lincar Accelerilli," Paper A-4, this conference. 